\title{
Modeling and Analysis of Supplier Selection Method Using Analytical Hierarchy Process (AHP)
}

\author{
Temesgen Garoma $^{1^{*}}$ and Shimels Diriba ${ }^{2}$ \\ ${ }^{1}$ Department of Mechanical Engineering, College of Engineering and Technology, Wollega University, \\ P.O. Box 395, Nekemte, Ethiopia. \\ ${ }^{2}$ School of Commerce, Addis Ababa University, P.O. Box 1888, Addis Ababa, Ethiopia
}

\begin{abstract}
This research paper deals with the development of supplier selection methodology for an organization. In today's dynamic environment supplier selection decision presents organizations with a complex scenario and the age old tradition of selecting suppliers based on solitary criteria, mainly price and the practice of engaging in adversarial relation with suppliers is only history. Supplier evaluation and selection is recognized as a multicriteria decision problem and the use of analytical and mathematical models is highly emphasized by professionals and researchers alike. However, in these parts of the world the application of tools and models for supplier selection problem is yet to surface and the banking and finance industry here in Ethiopia is no exception. Thus, the purpose of this research was to address supplier selection problem through modeling and application of analytical hierarchy process (AHP). As the result a model was developed via AHP and run using a historical data from AIB's (Awash International Bank S.C.) generator purchase and the result indicated that quality/technical has higher rank (46\%), price/cost $(25 \%)$, and followed by after sale service (11\%). Furthermore, delivery, financial position and reputation have all equal importance and attribute $6 \%$ each. The use of such technique will reduce the level of subjectivity in supplier evaluation and selection, and allows one to reach an optimal selection decision.
\end{abstract}

Article Information

Copyright@2014 STAR Journal. All Rights Reserved.

Article History:

Received : 20-01-2014

Revised : 15-03-2014

Accepted : 20-03-2014

Keywords:

Analytical Hierarchy Process

Multi-Criteria Decision Making

Supplier Selection

${ }^{*}$ Corresponding Author:

Temesgen Garoma

E-mail:

temgarom@yahoo.com

\section{INTRODUCTION}

Multiple-criteria decision making (MCDM) is considered as one of the rapidly growing areas of operations research dedicated to the provision of mathematical and analytical tools or mechanisms to tackle complex problems involving multiple criteria, goals, or objectives of conflicting nature. One of such Decision Support System (DSS) techniques is analytic hierarchy process (AHP) which enables users to solve a complex problem reducing it into simple pairwise permutation and comparisons of criteria. AHP was invented by Thomas Saaty (Helms, 2006).

Moreover, Saaty, is internationally recognized for invention of Analytic Hierarchy Process (AHP) and its generalization to network decisions, the Analytic Network Process (ANP) (Saaty, 2008).

Dong, Xu, Li and Dai (2007), also acknowledge Saaty's contribution to development analytic hierarchy process (AHP) and further sate that AHP is being widely applied in the past two decades in almost all decision making situations that had involved multiple criteria.

Amid the area of application for AHP is the supplier selection problem which involves multiple-criteria viz qualitative and quantitative variables and hence, number of studies had surfaced in recent years in relation to supplier selection problem using AHP (e.g. Ayhan, 2013; Chakraborty, Ghosh and Dan, 2011, Onder and Dag, 2013; Politis, Klumpp and Celebi, 2010; Prusak, Stefanów, Niewczas, and Sikora, 2013).

Aktepe and Ersoz (2011) noted that numerous extant studies using AHP to solve supplier selection problem had used different terminologies such as supplier selection, evaluation and development as their topic for investigations which apparently had dealt was similar issues and virtually considered identical in meaning.

According to Tahriri, Osman, Ali and Yusuff (2008), AHP is the most commonly used tool for supplier selection problem as compared to several other mathematical as well as analytical tools. This claim is also supported by a number of other studies (e.g. Ayhan, 2013; Chakraborty, Ghosh and Dan, 2011, Onder and Dag, 2013; Politis, Klumpp and Celebi, 2010; Prusak, Stefanów, Niewczas, and Sikora, 2013).

Thus, the purpose of this case study was to develop a model for supplier selection for Awash International Bank S.C. (AIB) which is a market leader in the private banking industry here in Ethiopia. 
Temesgen and Shimels

\section{Analytic Hierarchy Process (AHP)}

According to Tahriri, Osman, Ali and Yusuff (2008) who have made a review of supplier selection methods Analytical Hierarchical Process (AHP) rated as most widely used, easily understood and the best to combine both objective as well as subjective decisions. Moreover, they point out that the method employed for decision making can have a significant impact on the decision reached.

They further elucidate that, there are several well known selection methods that have been developed and classified by numerous scholars over the years: the categorical model, the weighted point model, Total cost approaches or the cost ratio method (Principal Component Analysis (PCA) and the Artificial Neural Network (ANN)), the Multiple Attribute Utility Theory (MAUT) method, Fuzzy logic approach and Analytical Hierarchical Process (AHP).

An extensive review of the supplier selection literature shows that among the methods mentioned in the preceding paragraph AHP is found to be one of the most commonly applied methods in practice (Tahriri, et. al, 2008).

Politis, Klumpp and Celebi, (2010) also support the position of Tahriri, et. al, (2008) that AHP provides a wellsubstantiated and easily comprehensible solution to supplier selection problem which makes it the most reliable decision making tool especially for groups decision making.

In addition, Chakraborty, Ghosh and Dan (2011) further support the idea that AHP has been widely recognized as supplier selection tool for decades (Narasimhan, 1983; Nydick et al., 1992; Partovi et al., 1989) attributing such popularity and recognition to the tools unique capability to deal with both quantifiable as well as unquantifiable criteria.

Further, Prusak, Stefanów, Niewczas, and Sikora (2013) labeled AHP as a superior model as compared to the DEA (Data Envelopment Analysis), MAUT (Multiattribute utility theory), TCO (Total cost of ownership) and statistical models; particularly, because of its simplicity, flexibility and availability of dedicated software to make quick calculation.

Ayhan (2013), who had also reviewed numerous extant literatures, makes distinction of methodologies used for supplier selection problem categorizing them as the best, most important and outranked. According to this classification AHP and MAUT are considered the best, while, Goal Programming and Topsis as most important and ELECTRE and PROMETHEE as the outranked methods.

Therefore, based on the preceding discussions it is evident that numerous accounts proclaim AHP as the best tool for decision making in supplier selection problem and this makes the basis for selecting this multiple criteria decision making tool for this particular case study.

\section{Decision Criteria and Alternatives}

Different studies have considered various criteria and variable range of alternatives. However, taking the
Sci. Technol. Arts Res. J., Jan-March 2014, 3(1): 145-151

procurement practice of AIB into account, almost all supplier selection problems involve at least three suppliers and preferably five or better. Therefore, an alternative of five has been adapted.

However, with regard to the criteria a review of literatures has been considered. The assessment of literatures revealed that variability in the criteria used is highly pronounced. For instance, Politis et al., (2010) had used delivery and quality as selection criteria attaching 90\% weight, while, Chakraborty et al., (2011), considered cost, quality and delivery. Yet another variation can be Prusak, Stefanów, Niewczas, and Sikora (2013) who had adapted price, assortment, logistics, service and quality.

Further, Onder and Dag (2013) considered criteria such as origin of raw material, quality, delivery, cost, availability and reliability in a similar fashion Ayhan (2013) employed quality, origin, cost, delivery and after sales.

More comprehensively Prusak et al. (2013) indicated that most frequently discussed criteria are price account $80 \%$ of the 74 reviewed articles, delivery (59\%) and quality (54\%). Perhaps one highly regarded work in this respect is the study by Aktepe and Ersoz (2011) who have reviewed the works of several authors outlining thirty five criteria (table, 1).

The table shows the different criteria used by different researchers for supplier selection over the years. Hence, analysis of the table indicated that among the thirty five criteria used five of them were used by more than half the research works outlined above and half of them had used additional one criterion (after sales service) (Aktepe and Ersoz, 2011). Similarly, Benyoucef, Ding and Xie (2003) who make references to one of earliest works in supplier selection criteria developed by Dickson (also mentioned in the above table) rate quality and delivery as extremely important; price, financial position and reputation as considerably important and repair or after sales service as an averagely important criteria.

Thus the six commonly used factors for supplier evaluations extracted from literatures are price, quality, delivery, financial position, reputation and position in the industry and after sales service.

\section{MATERIALS AND METHODS}

The type of research used for this study was case study which is a strategy of inquiry in whereby the researcher investigates in depth a program, activity or an event and collects a detailed information using a variety of data collection procedure over a sustainable period of time (Stake, 1995) as cited in (Creswell, 2009).

Hence, case study is considered for this research at least for three reasons; first, the purpose of the study is to investigate a single activity or process in business organization i.e. supplier selection process, second, the study was aimed at understanding the issue in depth, third, the study is restricted or limited to Awash International Bank's head office and finally, because case studies often use quantitative measures as pointed out by "yin and others (Glatthorn, 1998) and hence, this strategy fits very well with AHP since AHP considers both qualitative and quantitative criteria. 
Table 1: List of criteria used in supplier selection problem

\begin{tabular}{|c|c|c|c|c|c|c|c|c|c|c|}
\hline Criteria & Dickson & Lehmann & Abratt & Weber & Min & $\begin{array}{l}\text { Stravro- } \\
\text { polous }\end{array}$ & $\begin{array}{c}\text { Ghodsy } \\
\text {-pour }\end{array}$ & Chan & Chen & Lin \\
\hline Price & $x$ & $x$ & $X$ & $x$ & $\mathrm{X}$ & $\mathrm{X}$ & $x$ & $X$ & & \\
\hline Quality & $x$ & & & $\mathrm{X}$ & $x$ & & $x$ & $x$ & $x$ & \\
\hline Delivery & $x$ & $x$ & & $x$ & $x$ & & $x$ & $x$ & & \\
\hline Warranties and Claims & $x$ & $x$ & & & & & & & & \\
\hline After Sales Service & $x$ & $x$ & $x$ & $x$ & & & & $x$ & & \\
\hline Technical Support & & $x$ & $x$ & & & & & $x$ & & \\
\hline Training Aids & $x$ & $x$ & & $x$ & & & & & & \\
\hline Attitude & $x$ & & $x$ & $x$ & & & & & & \\
\hline Performance History & $x$ & & & $x$ & & & & $x$ & & \\
\hline Financial Position & $x$ & $x$ & & $x$ & & & & $x$ & $x$ & \\
\hline Geographical Location & $x$ & & & $x$ & & & & $x$ & & \\
\hline $\begin{array}{l}\text { Management and } \\
\text { Organization }\end{array}$ & $x$ & & & $x$ & & & & & & \\
\hline Labor Relations & $x$ & & & $x$ & & & & & & \\
\hline Communication System & $x$ & & & $x$ & & & & $\mathrm{x}$ & & $x$ \\
\hline $\begin{array}{l}\text { Response to Customer } \\
\text { Request }\end{array}$ & & $x$ & & & & & & $x$ & & \\
\hline $\begin{array}{l}\text { E-commerce Capability } \\
\text { JIT Capability }\end{array}$ & & & & & $x$ & $x$ & & & & \\
\hline Technical Capability & $x$ & & & $x$ & & & & & $x$ & \\
\hline $\begin{array}{l}\text { Production Facilities } \\
\text { and Capacity }\end{array}$ & $x$ & & & $x$ & & & $x$ & $x$ & & \\
\hline Packaging Ability & $x$ & & & $x$ & & & & & & \\
\hline Operational Controls & $x$ & & & $x$ & & & & & & \\
\hline Ease-of-Use & & $x$ & $x$ & & & & & & & \\
\hline Maintainability & & $x$ & $x$ & & & & & & & \\
\hline Amount of Past Business & $x$ & $x$ & & $x$ & & & & & & \\
\hline $\begin{array}{l}\text { Reputation and position } \\
\text { in industry }\end{array}$ & $x$ & $x$ & $x$ & $x$ & & & & $x$ & & $x$ \\
\hline $\begin{array}{l}\text { Reciprocal } \\
\text { Arrangements }\end{array}$ & $x$ & & & $x$ & & & & & & \\
\hline Impression & $x$ & $x$ & $x$ & $x$ & & & & & & \\
\hline $\begin{array}{l}\text { Environmentally Friendly } \\
\text { Products }\end{array}$ & & & & & $x$ & & & & & \\
\hline Product Appearance & & & & & & $x$ & & & & \\
\hline Catalog Technology & & & & & & $x$ & & & & \\
\hline Relationship Closeness & & & & & & & & & $x$ & $x$ \\
\hline Conflict Resolution & & & & & & & & & $x$ & $x$ \\
\hline Political Stability & & & & & & & & $x$ & & \\
\hline Economy & & & & & & & & $x$ & & \\
\hline Terrorism & & & & & & & & $x$ & & \\
\hline
\end{tabular}

Source: Aktepe and Ersoz (2011)

Hence, focused group discussion to rate the pair wise comparison of six criteria's were made by AIB procurement and materials management unit.

Supplier selection and evaluation process represents a typical multi-criteria decision making that entails multiple criteria involving both qualitative and quantitative factors. AHP is chosen because it permits decision makers to model a complex problem into a hierarchical structure showing the linkage amid, goal, criteria, and alternatives (Enyinda, Dunu and Bell-Hanyes, 2010). Moreover, AHP has been widely used in supplier selection (e.g., Aktepe and Ersoz, 2011; Tahriri, et. al; Chakraborty, Ghosh and Dan, 2011 and Politis, Klumpp and Celebi, 2010).

Hence, the overall methodology adopted for supplier selection process in AIB was composed of three levels as depicted in Figure 1. At the structural apex there is the overall goal of the problem, whereas the middle level is poised of the multiple selection criteria and finally, at the bottom level of the structure there are contending alternative suppliers.

\section{Procedure for Application of AHP Model}

To apply an AHP the following standard algorisms were employed which consists six steps with sub procedures.

Step 1: The problem is selecting the best supplier among five alternative suppliers which are $A, B, C, D$ and $E$ equipment suppliers of Awash International Bank S.C. The best alternative supplier must be selected according to six criteria which are six most addressed criteria in the literature (Aktepe and Ersoz, 2011) price/cost, quality/technical, delivery time, financial position, reputation and position in the industry and after sales service.

Step 2: Developing the hierarchical structure of the problem, as show on figure 1.

Step 3: The Saaty's scale of comparisons in a multicriteria decision making area in this study is given in Table 2. 


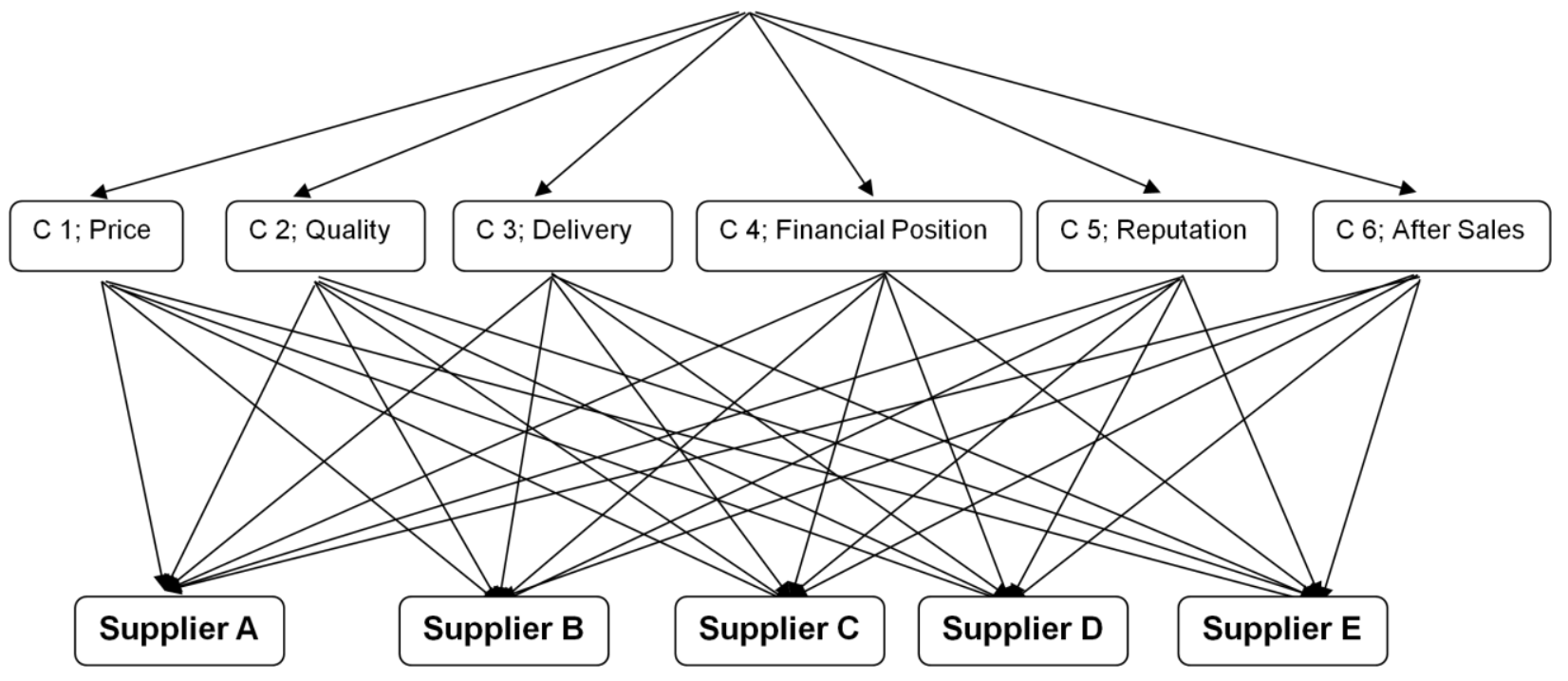

Figure 1: Hierarchical structure of the problem.

Table 2: The Saaty's scale of comparisons in a multi-criteria decision making.

\begin{tabular}{|c|c|}
\hline $\begin{array}{l}\text { Intensity of } \\
\text { Importance }\end{array}$ & Definition \\
\hline 1 & Equal Importance \\
\hline 2 & Weak or slight \\
\hline 3 & Moderate importance \\
\hline 4 & Moderate plus \\
\hline 5 & Strong importance \\
\hline 6 & Strong plus \\
\hline 7 & Very strong or demonstrated importance \\
\hline 8 & Very, very strong \\
\hline 9 & Extreme importance \\
\hline $\begin{array}{l}\text { Reciprocals } \\
\text { of above }\end{array}$ & $\begin{array}{l}\text { If activity } i \text { has one of the above non-zero } \\
\text { numbers assigned to it when compared with } \\
\text { activity } j \text {, then } j \text { has the reciprocal value when } \\
\text { compared with } i\end{array}$ \\
\hline
\end{tabular}

1.1-1.9 If the activities are very close

\begin{abstract}
Two activities contribute equally to the objective
Experience and judgment slightly favors one activity over another
\end{abstract}

Experience and judgment strongly favors one activity over another

An activity is favored very strongly over another; its dominance demonstrated in practice

The evidence favoring one activity over another is of the highest possible order of affirmation

\title{
A reasonable assumption
}

May be difficult to assign the best value but when compared with other contrasting activities the size of the small numbers would not be too noticeable, yet they can still indicate the relative importance of the activities.

\section{Source: (Saaty et al., 2008)}

Adoption of Saaty's scale is well supported by the study conducted by Kumar and Ganesh (1996) cited in Dong, Xu, Li and Dai (2007) which had compared different numerical scales and prioritizations and the result revealed that that prioritizations using the eigenvalue method (EVM) is better than the logarithmic least squares methods (LLSM) using the simulation method of Triantaphyllou and Mann (1990).

Step 4: Construct a set of pair-wise comparison matrices. Each element in an upper level is used to compare the elements in the level immediately below with respect to it (Saaty et al., 2008).

Step 5: (Perform consistency check) Prof. Saaty proved that for consistent reciprocal matrix, the largest Eigen value is equal to the size of comparison matrix, or max $\lambda=$ $n$. Then he gave a measure of consistency, called
Consistency Index as deviation or degree of consistency using the following formula (www.Revoledu.com).

$$
\mathrm{CI}=\frac{\lambda \max -\mathrm{n}}{n-1}
$$

Then, he proposed what is called Consistency Ratio, which is a comparison between Consistency Index and Random Consistency Index, or in formula, (www.Revoledu.com).

$$
\mathrm{CR}=\frac{\mathrm{CI}}{R I}
$$

If the value of Consistency Ratio is smaller or equal to $10 \%$, the inconsistency is acceptable. If the Consistency Ratio is greater than $10 \%$, we need to revise the subjective judgment however, in practice, you don't need $\mathrm{RI}$ for more than $\mathrm{n}=7$ because the number of pair comparisons $n^{*}(n-1) / 2$ become so large. Final, we utilize 
Temesgen and Shimels

the hierarchy by grouping some criteria into a higher level hierarchy of the criteria (table 3 and 4).

Sci. Technol. Arts Res. J., Jan-March 2014, 3(1): 145-151

For the particular problem structure the numbers of comparisons are 15 which are calculated as follows.

$$
\mathrm{N}=\frac{6(6-1)}{2}=30 / 2=15
$$

Table 3: Number of comparison

\begin{tabular}{ccccccccc}
\hline Number of Criteria & 1 & 2 & 3 & 4 & 5 & 6 & 7 & $\mathrm{~N}$ \\
\hline Number of comparison & 0 & 1 & 3 & 6 & 10 & 15 & 21 & $\frac{\mathrm{n}(\mathrm{n}-1)}{2}$ \\
\hline
\end{tabular}

Table 4: Random Index (R.I)

\begin{tabular}{|c|c|c|c|c|c|c|c|c|c|c|c|c|c|c|c|}
\hline $\begin{array}{l}\text { Matrix } \\
\text { Size }\end{array}$ & 1 & 2 & 3 & 4 & 5 & 6 & 7 & 8 & 9 & 10 & 11 & 12 & 13 & 14 & 15 \\
\hline R.I. & 0 & 0 & 0.58 & 0.90 & 1.12 & 1.24 & 1.32 & 1.41 & 1.45 & 1.49 & 1.51 & 1.48 & 1.56 & 1.57 & 1.59 \\
\hline
\end{tabular}

The Random Index (R.I) shown in table 4 contains the random index values calculated from randomly generated weights as a function of the pair-wise matrix size or number of criteria (Ravindran, 2009).

Step 6: Use the priorities obtained from the comparisons to weigh the priorities in the level immediately below. Do this for every element. Then for each element in the level below add its weighed values and obtain its overall or global priority. Continue this process of weighing and adding until the final priorities of the alternatives in the bottom most level are obtained (Saaty et al., 2008).

\section{RESULTS}

The hierarchical structure of the supplier selection model is shown in figure 1 . As per the procurement practice of AIB, five alternative suppliers A, B, C, D and E whose names are not mentioned for confidentiality are considered and six criteria were adopted for evaluation that are quality, price, delivery, financial position, reputation and after sales service.

The pair-wise comparison matrix shown in table 5 is scored by the AIB's procurement and materials management unit using the given questioner and focused group discussion.

Table 5: Pairwise Comparison matrix for the six criteria.

\begin{tabular}{lcccccc}
\hline & $\begin{array}{c}\text { Price/ } \\
\text { Cost }\end{array}$ & $\begin{array}{c}\text { Quality/ } \\
\text { Technical }\end{array}$ & Delivery & $\begin{array}{c}\text { Financial } \\
\text { position }\end{array}$ & Reputation & $\begin{array}{c}\text { After sales } \\
\text { service }\end{array}$ \\
\hline Price/Cost & 1 & $1 / 3$ & 5 & 5 & 5 & 3 \\
Quality/Technical & 3 & 1 & 7 & 7 & 7 & 4 \\
Delivery & $1 / 5$ & $1 / 7$ & 1 & 1 & 1 & $1 / 2$ \\
Financial Position & $1 / 5$ & $1 / 7$ & 1 & 1 & 1 & $1 / 2$ \\
Reputation & $1 / 5$ & $1 / 7$ & 1 & 1 & 1 & $1 / 2$ \\
After sales service & $1 / 3$ & $1 / 4$ & 2 & 2 & 2 & 1 \\
\hline \multicolumn{1}{c}{ Total } & $\mathbf{7 4 / 1 5}$ & $\mathbf{1 6 9 / 5 4}$ & $\mathbf{1 7}$ & $\mathbf{1 7}$ & $\mathbf{1 7}$ & $\mathbf{1 9 / 2}$ \\
\hline
\end{tabular}

The synthesized matrix for the six supplier selection criteria is shown in Table 6. For example, the priority vector associated with price is obtained as follows: $(0.2027+0.1657+0.2941+0.2941+0.3158) / 6=0.2611$.
The reminder of the priorities for quality/ technical, delivery, financial position, reputation and after sales are $0.4602,0.0568,0.0568,0.0568$ and 0.1083 respectively.

Table 6: Synthesized (or Normalized) Matrix for the Six Criteria.

\begin{tabular}{lccccccc}
\hline & $\begin{array}{c}\text { Price/ } \\
\text { Cost }\end{array}$ & $\begin{array}{c}\text { Quality/ } \\
\text { Technical }\end{array}$ & Delivery & $\begin{array}{c}\text { Financial } \\
\text { position }\end{array}$ & Reputation & $\begin{array}{c}\text { After sales } \\
\text { service }\end{array}$ & Priority \\
\hline Price/Cost & 0.2027 & 0.1657 & 0.2941 & 0.2941 & 0.2941 & 0.3158 & 0.2611 \\
Quality/ Technical & 0.6081 & 0.4970 & 0.4118 & 0.4118 & 0.4118 & 0.4211 & 0.4602 \\
Delivery & 0.0405 & 0.0710 & 0.0588 & 0.0588 & 0.0588 & 0.0526 & 0.0568 \\
Financial position & 0.0405 & 0.0710 & 0.0588 & 0.0588 & 0.0588 & 0.0526 & 0.0568 \\
Reputation & 0.0405 & 0.0710 & 0.0588 & 0.0588 & 0.0588 & 0.0526 & 0.0568 \\
After sales service & 0.0676 & 0.1243 & 0.1176 & 0.1176 & 0.1176 & 0.1053 & 0.1083 \\
\hline
\end{tabular}

Tables 7-12 show the pairwise comparison matrices of five suppliers with respect to each criterion and priorities. This process is similar to the procedure used to create the criteria comparison matrix. For example, the purchasing and materials management section head compare each pair of suppliers with respect to price/cost, quality/technical, delivery, reputation, after sales service and financial position. And the priorities of the suppliers, for each criterion, derived employing the four steps procedure identified in the procedure for application section. 
Table 7: Pairwise comparison with respect to price/cost

\begin{tabular}{lcccccc}
\hline Price/Cost & Supplier A & Supplier B & Supplier C & Supplier D & Supplier E & Priority \\
\hline Supplier A & 1 & 2 & 2 & $1 / 3$ & 1 & 0.1717 \\
Supplier B & $1 / 2$ & 1 & 1 & $1 / 5$ & $1 / 2$ & 0.0891 \\
Supplier C & $1 / 2$ & 1 & 1 & $1 / 5$ & $1 / 2$ & 0.0891 \\
Supplier D & 3 & 5 & 5 & 1 & 3 & 0.4786 \\
Supplier E & 1 & 2 & 2 & $1 / 3$ & 1 & 0.1717 \\
\hline \multicolumn{7}{r}{} \\
\cline { 2 - 6 }
\end{tabular}

Table 8: Pairwise comparison with respect to quality/technical.

\begin{tabular}{ccccccc}
\hline Quality/technical & Supplier A & Supplier B & Supplier C & Supplier D & Supplier E & Priority \\
\hline Supplier A & 1 & 1 & 3 & 3 & 5 & 0.3474 \\
Supplier B & 1 & 1 & 3 & 3 & 5 & 0.3474 \\
Supplier C & $1 / 3$ & $1 / 3$ & 1 & 1 & 2 & 0.1202 \\
Supplier D & $1 / 3$ & $1 / 3$ & 1 & 1 & 2 & 0.1202 \\
Supplier E & $1 / 5$ & $1 / 5$ & $1 / 2$ & $1 / 2$ & 1 & 0.0648 \\
\hline
\end{tabular}

Table 9: Pairwise comparison with respect to delivery.

\begin{tabular}{ccccccc}
\hline Delivery & Supplier A & Supplier B & Supplier C & Supplier D & Supplier E & Priority \\
\hline Supplier A & 1 & $1 / 3$ & 1 & $1 / 3$ & $1 / 3$ & 0.1251 \\
Supplier B & 3 & 1 & 3 & 1 & 1 & 0.3754 \\
Supplier C & 1 & $1 / 3$ & 1 & $1 / 3$ & $1 / 3$ & 0.1251 \\
Supplier D & $1 / 3$ & 1 & $1 / 3$ & 1 & 1 & 0.1872 \\
Supplier E & $1 / 3$ & 1 & $1 / 3$ & 1 & 1 & 0.1872 \\
\hline \multicolumn{7}{r}{} \\
\hline
\end{tabular}

Table 10: Pair wise comparison with respect to financial position.

\begin{tabular}{ccccccc}
\hline Financial Position & Supplier A & Supplier B & Supplier C & Supplier D & Supplier E & Priority \\
\hline Supplier A & 1 & 3 & 1 & 5 & 5 & 0.3642 \\
Supplier B & $1 / 3$ & 1 & $1 / 3$ & 2 & 2 & 0.1309 \\
Supplier C & 1 & 3 & 1 & 5 & 5 & 0.3642 \\
Supplier D & $1 / 5$ & $1 / 2$ & $1 / 5$ & 1 & 1 & 0.0703 \\
Supplier E & $1 / 5$ & $1 / 2$ & $1 / 5$ & 1 & 1 & 0.0703 \\
\hline
\end{tabular}

Table 11: Pair wise comparison with respect to reputation.

\begin{tabular}{ccccccc}
\hline Reputation & Supplier A & Supplier B & Supplier C & Supplier D & Supplier E & Priority \\
\hline Supplier A & 1 & 3 & 1 & 5 & 5 & 0.3642 \\
Supplier B & $1 / 3$ & 1 & $1 / 3$ & 2 & 2 & 0.1309 \\
Supplier C & 1 & 3 & 1 & 5 & 5 & 0.3642 \\
Supplier D & $1 / 5$ & $1 / 2$ & $1 / 5$ & 1 & 1 & 0.0703 \\
Supplier E & $1 / 5$ & $1 / 2$ & $1 / 5$ & 1 & 1 & 0.0703 \\
\hline \multicolumn{7}{r}{} \\
\hline
\end{tabular}

Table 12: Pair wise comparison with respect to after sales.

\begin{tabular}{ccccccc}
\hline After Sales & Supplier A & Supplier B & Supplier C & Supplier D & Supplier E & Priority \\
\hline Supplier A & 1 & 5 & 1 & 5 & 5 & 0.5197 \\
Supplier B & $1 / 5$ & 1 & $1 / 5$ & 1 & 1 & 0.1039 \\
Supplier C & 1 & $1 / 5$ & 1 & $1 / 5$ & $1 / 5$ & 0.1685 \\
Supplier D & $1 / 5$ & 1 & $1 / 5$ & 1 & 1 & 0.1039 \\
Supplier E & $1 / 5$ & 1 & $1 / 5$ & 1 & 1 & 0.1039 \\
\hline
\end{tabular}

Table 13: Priority matrix of supplier selection alternatives.

\begin{tabular}{lcccccc}
\hline & Supplier A & Supplier B & Supplier C & Supplier D & Supplier E & Preference Vector \\
\hline Price/Cost & 0.1717 & 0.0891 & 0.0891 & 0.4780 & 0.1717 & 0.2610 \\
Quality/ Technical & 0.3474 & 0.3474 & 0.1202 & 0.1202 & 0.0648 & 0.4602 \\
Delivery & 0.1251 & 0.3754 & 0.1251 & 0.1872 & 0.1872 & 0.0568 \\
Financial position & 0.3642 & 0.1309 & 0.3642 & 0.0703 & 0.0703 & 0.0568 \\
Reputation & 0.3642 & 0.1309 & 0.3642 & 0.0703 & 0.0703 & 0.0568 \\
After sales service & 0.5197 & 0.1309 & 0.1685 & 0.1039 & 0.1039 & 0.1113 \\
\hline Overall Priority Vector & $\mathbf{0 . 3 1}$ & $\mathbf{0 . 2 3}$ & $\mathbf{0 . 1 5}$ & $\mathbf{0 . 2 1}$ & $\mathbf{0 . 1 0}$ & $\mathbf{1 . 0 0}$ \\
\hline
\end{tabular}




\section{Temesgen and Shimels}

With respect to the overall priority scores of alternative suppliers it is obtained by calculating overall priority or global priorities of supplier. To calculate supplier A's global priority A, Global priority $A=0.1717(0.2611)+$ $0.13474(0.4602)+0.1251(0.0568)+0.3642(0.0568)+$ $0.3642(0.0568)+0.5197(0.1083)=0.31$ By doing similar algorisms for all suppliers results in global priority $\mathrm{B}=$ 0.23 , global priority $C=0.15$, global priority $D=0.21$, and global priority $\mathrm{E}=0.10$.

Hence, supplier A with global priority equal to 0.31 is most preferred followed by supplier B $(0.23)$, supplier $D$ (0.21), supplier $C(0.15)$ and supplier $E(0.1)$, respectively. That is, supplier A> supplier B > supplier D > supplier $C>$ supplier E. Essentially, supplier $A$ is judged to be the overall best.

\section{DISCUSSION}

The criteria rating practice at AIB revealed that quality/technical is rated higher than any of six criteria considered for evaluation and selection. This practice of assigning the highest weight for quality is well supported by several other studies (Chakraborty et al., 2011; Politis, et al., 2010; Hudymáčová et al., 2010).

The result also indicated that supplier " $A$ " is most preferred to all other suppliers which is the same as the decision made by the procurement and materials management unit of AIB. However, contrary to the decision of the procurement unit are suppliers " $C$ " and " $D$ " which are ranked in reversed orders as fourth and third preferred suppliers respectively. Nonetheless it has to be noted that current procedure for supplier selection at AIB is nearly perfectly matches with the result obtained using AHP.

Another point worth mentioning here can be the recreation by the procurement and materials management unit to the tool: the unit indicated that AHP is an easier tool to use as compared to the traditional method of scoring but more importantly, it reduces the subjectivity involved.

\section{CONCLUSION}

The research had introduced and demonstrated the use of analytical hierarchy process (AHP) for supplier selection in the banking industry. It is believed that AHP is quiet a powerful model particularly in multi-criteria decision making. Given the complexity of the problem in supplier selection especially in large purchases AHP can be considered as an ideal tool. However, it was evident that AIB's procurement unit was unfamiliar AHP and arguably the Ethiopian banking industry.

Hence, the mission is to introduce the concept had been successful. Moreover, it ensure the validity of the measurement of criteria for supplier evaluation and selection criteria had been extracted from literatures and further a historical data from AIB's generator procurement was employed for application. The result indicated that the unit uses similar mechanisms that sharply correspond to AHP thus the introduction of AHP would help formalize their effort. To this end AIB's procurement unit is considering the use of AHP with collaboration of its technique department which takes the leading position in criteria development.
Sci. Technol. Arts Res. J., Jan-March 2014, 3(1): 145-151

\section{REFERENCES}

Aktepe, A. and Ersoz, S (2011). A fuzzy analytic hierarchy process model for supplier selection and a case study. International Journal of Research and Development 3(1): 33-37.

Ayhan, M., B. (2013). A fuzzy AHP approach for supplier selection problem: a case study in a Gearmotor company, International Journal of Managing Value and Supply Chains 4(3): 11-23.

Benyoucef, L., Ding, H. and Xie, X. (2003). Supplier selection problem: criteria and methods. Institut National de Recherche en Informatique et en Automatique Theme 4 and No: 4726, 1-38.

Chakraborty, T., Ghosh, T. and Dan, P.K. (2011). Application of analytic hierarchy process and heuristic algorithm in solving vendor selection problem. Business Intelligence Journal 4(1): 167-177.

Creswell, J.W. (2009). Research design: Qualitative, quantitative and mixed methods approaches ( $3^{\text {rd }}$ ed.). London: Sage Publication Inc.

Dong, Y., Xu, Y., Li, H. and Dai, M. (2007). A comparative study of the numerical scales and the prioritization methods in AHP. European Journal of Operational Research 186(2008): 229-242.

Enyinda, C.A., Dunu, E. and Bell-Hanyes, J. (2010). A model for quantifying strategic supplier selection: evidence from a generic pharmaceutical firm supply chain. International Journal of Business, Marketing, and Decision Sciences 3(2): 23-44

Hudymáčová, M., Benková, M., Pócsová, J. and Škovránek, T. (2010). Supplier selection based on multi-criterial AHP method. Acta Montanistica Slovaca 15(3): 249-255.

Glatthorn, A. (1998). Writing the winning dissertation: A stepby-step-guide. London: Corwin Press Inc

Helms, M.M. (2006 (Eds.)). Encyclopedia of management, $5^{\text {th }}$ Ed. : New York, Thomas Gale.

Onder, E. and Dag, S. (2013). Combining Analytical Hierarchy Process and Topsis approaches for supplier selection in a cable company. Journal of Business, Economics and Finance 2(2): 56-74.

Politis, S., Klumpp M. and Celebi, (2010). Analytical hierarchy process in supplier evaluation, In: Grubbström, R.W./Hinterhuber, H.H. (eds.): $16^{\text {th }}$ International Working Seminar on Production Economics, Conference Proceedings, Innsbruck 01-05.03.2010, Innsbruck (Eigenverlag), 3, Pp. 411-424.

Prusak, A.; Stefanów, P.; Niewczas, M. and Sikora, T. (2013). APPLICATION OF The AHP in evaluation and selection of suppliers, 57th EOQ Congress Quality Renaissance -Co-creating a Viable Future June 17-20, 2013, Tallinn, Estonia.

Saaty, T.L. (2008). Decision making with the analytic hierarchy process. International Journal of Services Sciences 1(1): 83-98.

Ravindran, A. R. (Eds.) (2009). Operations Research: Applications: New York, CRC Press; Taylor and Francis Group.

Tahriri, F., Osman, M.R., Ali, A. and Yusuff, R.M. (2008). A review of supplier selection methods in manufacturing industries. Suranaree Journal of Science and Technology 15(3): 202-208

Teknomo, K. (2006). Analytic Hierarchy Process (AHP) Tutorial. Available at http://people.revoledu.com/. 